\title{
Educação Infantil em museus de arte, ciência e história
}

\section{Young children's education in museums of art, science and history}

\author{
Thamiris Lopes* \\ Cristina Carvalho*
}

\begin{abstract}
RESUMO
Este artigo resulta de uma pesquisa de doutorado que investigou o público de Educação Infantil em museus de arte, ciência e história ${ }^{1}$. Apresentamos parte dos achados da pesquisa no que se refere a como as crianças reagem a essa experiência. Para tanto, foi priorizada a abordagem de pesquisa qualitativa, com realização de pesquisa de campo em museus de tipologias distintas, localizados na cidade do Rio de Janeiro. Questionário online, observação, entrevista e análise documental foram utilizados como ferramentas metodológicas. A reflexão acerca da formação humana, pautada nas experiências em meio à cultura e às manifestações culturais, artísticas e estéticas teve como alicerce as perspectivas teóricas de autores da área da Educação, Infância, Estética e Museologia que contribuíram para o constructo teórico da pesquisa. Os resultados apontam que a experiência das crianças nos espaços museais se constitui na interação com outros (pares, mediadores, professores) e com as manifestações, registros e celebração das diferentes formas de viver e estar no mundo. Conclui-se que, por meio de mediações e ações educativas adequadas, os museus podem ser compreendidos enquanto meio - experimental e criativo - profícuo para promover às crianças o encontro com a cultura.
\end{abstract}

Palavras-chave: Infância. Educação Infantil. Museus.

* Pontifícia Universidade Católica do Rio de Janeiro. Rio de Janeiro, Rio de Janeiro, Brasil. E-mail: thamiris_bl@hotmail.com - https://orcid.org/0000-0002-6317-9592 E-mail: cristinacarvalho@puc-rio.br - http://orcid.org/0000-0001-5261-0474

1 A pesquisa foi realizada com apoio da Coordenação de Aperfeiçoamento de Pessoal de Nível Superior - Brasil (CAPES) - Código de Financiamento 001. 


\begin{abstract}
This article is the doctoral research result used to investigate the Early Childhood Education public in art, science, and history museums. We present part of the research findings concerning how children react to this experience. To this end, we prioritized the qualitative research approach, with field research carried out in museums of different types located in Rio de Janeiro. We used an online questionnaire, observation, interview, and document analysis were used as methodological tools to carry out the study. The reflection on human formation, based on experiences amid the culture and cultural, artistic, and aesthetic manifestations were based on authors' theoretical perspectives in the Education, Childhood, Aesthetics, and Museology fields that contributed to the theoretical construct of research. The results show that the children's experience in the museum constituted the interaction with others (peers, mediators, teachers) and the manifestations, records, and celebration of the different ways of living and being in the world. It is concluded that, through appropriate mediations and educational activities, museums can be understood as a means - experimental and creative - beneficial to promote children the encounter with culture.
\end{abstract}

Keywords: Childhood. Early Childhood Education. Museums.

\title{
Introdução
}

Historicamente, o conceito e o olhar sobre a infância foram se modificando e influenciando diretamente as políticas públicas voltadas ao atendimento das peculiaridades apresentadas nessa etapa da vida. Perceber as crianças enquanto cidadãos, sujeitos sociais e históricos, produtores de cultura é condição para que se atue no sentido de favorecer seu crescimento e constituição.

Compreendendo que as experiências com as expressões culturais diversas levam a criança a interagir e se apropriar do mundo, construindo significações e estabelecendo inúmeras relações, os museus - lugares que guardam diferentes saberes culturais produzidos pela humanidade - são espaços que podem contribuir para sua formação. Por guardar e comunicar de forma diferenciada os diferentes testemunhos da cultura material, podem provocar curiosidade, admiração, encantamento, estranhamento, discordância - dentre tantos outros sentimentos - de modo a impulsionar a criança a desvendar o sentido dos objetos, com uma postura crítica e investigativa perante as coisas do mundo. 
Contudo, alguns estudos ${ }^{2}$, na literatura nacional e internacional, reiteram o quanto as práticas e políticas museais, historicamente, reproduziram o sistema de desigualdades preexistente na sociedade, principalmente no que diz respeito ao acolhimento às crianças em seus espaços. Esses estudos sinalizam alguns apontamentos sobre a atuação inadequada na recepção às crianças. Geralmente, essa inadequação se refere ao fato de os profissionais dos museus adultizarem as crianças, ou usarem um vocabulário infantilizado, ignorando suas falas e, principalmente, desconsiderando aspectos importantes na forma como a criança se apropria do mundo, como a interatividade, a ludicidade e a possibilidade de fantasia e imaginação. Para além desses fatores, outro conflito constantemente encontrado é que o comportamento social próprio da criança, geralmente, difere do esperado ao se frequentar os espaços museológicos. A expectativa é a da não ação - prestar atenção, escutar os mediadores, aguardar o momento correto para falar, permanecer com os braços para trás ou de mãos dadas com outra criança. Esse comportamento desejado contraria os modos da criança apreender e se apropriar da cultura, de imaginar e de estabelecer conexões (GABRE, 2016; POL; ASENSIO, 2006; CARVALHO, 2013, 2016; CARVALHO; LOPES, 2016; OLIVEIRA, 2011; LEITE, 2005, 2011).

Considerando a potência que os espaços museais podem alcançar contribuindo para uma formação humana, desde a mais tenra idade, e os obstáculos que se apresentam para o desenvolvimento de tal função, este artigo apresenta os principais achados de uma pesquisa de doutorado que buscou entender como se dá, atualmente, a relação do público infantil com os museus.

Como recorte de pesquisa, foi escolhido o público infantil escolar, pois, dentre as inúmeras possibilidades a serem exploradas, é preciso distinguir a especificidade da experiência coletiva quando as crianças visitam os museus com a escola. O passeio em si já é suficiente em termos de novidades a serem assimiladas: sair para o desconhecido sem a família, perder as referências, pegar o ônibus, observar o caminho percorrido pela cidade, chegar a um espaço arquitetônico que muitas vezes é suntuoso e, ainda, a peculiaridade de viver tudo isso acompanhado de outras crianças e não apenas de adultos. Reconhecer a importância dessa experiência coletiva significa perceber o papel fundamental das interações sociais para a construção do conhecimento em meio à formação cultural das crianças (MOURA, 2011; FALLON; CHAVEPEYER, 2013; LOPES, 2019).

2 Carvalho (2013), Leite (2005, 2011), Reddig (2007), Pol e Asensio (2006), Fallon e Chavepeyer (2013), Shaffer (2015). 
Investigar a relação entre o público de Educação Infantil (E.I) e os museus implica estar atento aos diversos elementos envolvidos nessa relação: o espaço, o acervo, o trabalho dos mediadores e dos professores e (não somente) as crianças. Da parte dos museus, é preciso saber qual a relação que estabelecem com o público infantil, as atividades desenvolvidas, as metodologias implementadas, observar a utilização dos espaços expositivos com as crianças etc. Investigar como essa relação se dá para as crianças também é um aspecto importante, ou seja, perceber, de modo geral, como reagem à experiência de visitar museus com a escola, descobrir suas expectativas, o que dizem, como se comportam, o que desperta maior interesse, quais conhecimentos e interpretações conseguem articular. Outro aspecto a ser compreendido é a forma como os professores participam dessa relação: se existe preferência por algum tipo de museu, o que pretendem proporcionar às crianças com as visitas e como se relacionam com o conteúdo das exposições/com os mediadores/com as crianças.

Considerando tais objetivos, a pesquisa foi desenvolvida por meio da abordagem qualitativa, que se mostrou a mais adequada por ser um meio de produção de conhecimento que não busca mensurar e medir, mas sim compreender e buscar explicações para valores e significados de um meio social. Questionário online, observação, entrevista e análise documental foram as ferramentas metodológicas utilizadas.

Os dados iniciais para o desenvolvimento da pesquisa foram obtidos por meio de um questionário online que proporcionou a coleta e construção de uma Base de Dados produzida pelo Grupo de Pesquisa em Museus, Cultura e Infância (GEPEMCI / PUC-Rio). A pesquisa do Grupo teve como objetivo mapear e conhecer os setores educativos de museus e centros culturais da cidade do Rio de Janeiro com o intuito de identificar as atividades oferecidas ao público - e mais especificamente às crianças de 0 a 6 anos -, a estrutura de funcionamento mantida pelas instituições, os agentes sociais que neles atuavam e, principalmente, as estratégias pedagógicas desenvolvidas nesses espaços.

A partir da análise dos resultados, foi possível elencar as três instituições museais da cidade que, na época, apresentavam maior profusão de possibilidades para a investigação. Possuíam programação específica para turmas de Educação Infantil e demanda de agendamento para visitas escolares desse segmento. Foram elas: Museu de Arte do Rio, Casa da Ciência da Universidade Federal do Rio de Janeiro (UFRJ) e Museu Casa de Rui Barbosa.

A observação em campo nas instituições supracitadas considerou os desafios éticos e metodológicos, principalmente, no que se refere às especificidades de pesquisa com crianças (no que tange a observar, escutar, perceber e olhar como as crianças reagem à experiência com o museu, com os professores e com os mediadores). Para tanto, seguiu-se um roteiro previamente estruturado 
e autorizado constituído de cinco categorias: I - tópicos a serem observados nas crianças; II - tópicos a serem observados nos educadores dos museus; III - tópicos a serem observados nas atividades realizadas; IV - tópicos a serem observados nos professores; e IV - tópicos a serem observados no espaço expositivo.

Também foram realizadas entrevistas semiestruturadas com os mediadores, com os coordenadores responsáveis pelos setores educativos de cada instituição e com professores em visita com suas turmas. As entrevistas tiveram como objetivo entender como esses profissionais concebiam a relação do público de E.I com aqueles espaços - possibilidades, desejos e obstáculos que se apresentavam. Efetivou-se também análise documental de todos os materiais obtidos na internet e/ou cedidos pelas próprias instituições.

Durante os sete meses de realização do campo, foram feitas 12 observações de visitas escolares de E.I nos três museus selecionados. Participaram da pesquisa 329 crianças e 14 professores. Em relação aos profissionais dos museus, foram entrevistados 7 mediadores e 3 coordenadoras dos setores educativos ${ }^{3}$.

Neste artigo, nos concentramos em apresentar os achados da pesquisa no que se refere a como as crianças reagem à experiência de visitar museus de diferentes temáticas com suas escolas. O que dizem? Como se comportam? O que desperta maior interesse? Quais conhecimentos e interpretações conseguem articular? Apresentamos, principalmente, a discussão concernente à dimensão estética do conhecimento que pode ser propiciada no encontro das crianças com os museus ${ }^{4}$.

\section{Infância e a dimensão estética do conhecimento em museus}

Para Vigotski (2009), a possibilidade de criação humana, em qualquer etapa da vida, é ancorada na experiência. $\mathrm{O}$ autor sugere que, desde a infância, se viabilize a ampliação de experiências em meio ao conhecimento cultural produzido historicamente pela humanidade para que sejam criadas bases suficientemente sólidas para a atividade de criação. O teórico entende que

3 A pesquisa foi realizada com a devida autorização institucional de cada museu. As entrevistas ocorreram mediante termo de autorização e consentimento dos entrevistados que não são identificados, foram utilizados nomes fictícios. Nas observações em campo, autorizada por cada museu, também é garantido o anonimato de todas as escolas, professores, crianças e mediadores participantes.

4 A tese com os resultados completos da pesquisa está disponível em: www.dbd.puc rio.br/ pergamum/tesesabertas/1513194_2019_completo.pdf. 
"quanto mais a criança viu, ouviu e vivenciou, mais ela sabe e assimilou; quanto maior a quantidade de elementos da realidade de que ela dispõe em sua experiência - sendo as demais circunstâncias as mesmas -, mais significativa e produtiva será a atividade de sua imaginação" (VIGOTSKI, 2009, p. 23).

Pillar (2011) corrobora a perspectiva defendida pelo autor ao afirmar que a forma de perceber e apreender o mundo tem sempre a marca do conhecimento e da imaginação de quem observa, ou seja, depende do sujeito e das estruturas mentais que possui no momento. Diferentes pessoas podem ler uma mesma realidade e chegar a conclusões bem distintas. Isto porque o olhar de cada um é impregnado de experiências anteriores, associações, lembranças, fantasias, interpretações etc. Desse modo, podemos lançar diferentes olhares e realizar uma pluralidade de leituras sobre as distintas formas de existir no mundo.

Martins, Picosque e Guerra (1998) destacam que muito do que sabemos sobre o pensamento e o sentimento dos mais diversos povos, países, épocas e pessoas são oriundos de conhecimentos que obtivemos única e exclusivamente por meio de suas músicas, teatro, poesia, pintura, dança, cinema etc. É por meio das linguagens artísticas que também podemos compreender o mundo das culturas e a constituição do sujeito particular. Nesse processo, que envolve a compreensão e a interpretação das formas sensíveis e subjetivas que compõem a humanidade e suas diversas culturas, inúmeras fronteiras que compõem a constituição de si podem ser ultrapassadas. Entendendo que as formas de ver e estar no mundo pela experiência (que é tangenciada pela percepção do sensível) possui aspecto fundamental no processo de formação do sujeito, os estudos de Dewey (2010) e Vigotski $(1998,2003)$ - específicos sobre a discussão da experiência e da educação com a estética, dentre outros trabalhos -, ajudam a esclarecer o tema.

No que se refere ao entendimento acerca da experiência estética, Dewey (2010) considera que esta é a experiência em sua íntegra. É um desafio ao pensamento, pois exige evocação e organização, através da imaginação, por parte daquele que a vive. Todos os elementos que constituem o sujeito, advindos de outras experiências, se fundem na experiência estética.

$\mathrm{Na}$ concepção do autor, o traço distintivo da experiência estética é exatamente o fato de que, nela, não existe distinção entre o eu e o objeto/meio. A experiência é estética na medida em que o organismo e o meio cooperam na constituição de uma experiência na qual ambos ficam tão plenamente integrados que desaparecem (DEWEY, 2010).

Ressalta, ainda, que a experiência do ser humano é passível de uma qualidade estética, pois o mundo é uma combinação de movimento e culminâncias, de rupturas e reencontros. O indivíduo perde e reestabelece repetidamente o equilíbrio com o meio circundante e o momento de passagem 
da perturbação para a harmonia é o de vida mais intensa. Os estudos de Vigotski (1998) sobre a reação estética se alinham com a perspectiva de Dewey (2010) no que se refere a essa especificidade. Para o autor, todo comportamento humano também constitui um processo em busca de equilíbrio do indivíduo com o meio.

Quanto mais simples e elementares são nossas relações com o meio, tanto mais elementar é o transcorrer do nosso comportamento. Quanto mais complexa e delicada se torna a relação entre o organismo e o meio, tanto mais ziguezagueantes e confusos se tornam os processos de equilibração. Nunca se pode admitir que essa equilibração se realize até o fim de maneira harmoniosa e plena, sempre haverá certa vantagem da parte do meio ou do organismo (VIGOTSKI, 1998, p. 311).

Sobre a busca do equilíbrio no processo de viver, Dewey (2010) destaca que os seres humanos precisam de ordem, mas também demandam a novidade sob o viés de novas experiências. Nesse processo, a confusão é desagradável, mas o tédio também o é. O processo da vida orgânica é a variação e todo movimento da experiência que, ao se completar, retorna ao começo (carregada das bagagens da viagem) já que é uma satisfação da necessidade instigadora inicial.

De acordo com Vigotski $(1998,2003)$, essa necessidade instigadora inicial é decorrente do fato que as possibilidades do ser humano superam suas atividades, o organismo percebe muito mais atrações e estímulos do que pode realizar. Em sua relação com o mundo, o indivíduo sublima - definido pelo autor como "transformações dos tipos de energia psíquica não-consumidos e que não encontram saída na atividade normal do organismo em tipos superiores de energia" (VIGOTSKI, 2003, p. 231) - apenas uma parte insignificante de todas as excitações que surgem em seu sistema nervoso. A diferença entre as possibilidades e a realização é resgatada no ato de criação.

Como na natureza a parte realizada da vida representa uma parcela ínfima de toda a vida que poderia ter surgido, como cada vida que nasce deve-se a milhões de vidas que não nascem, assim, no nosso sistema nervoso, a parte da vida realizada supõe a parte menor da realmente contida em nós (...) O organismo foi colocado em certo equilíbrio com o meio, é necessário regular a balança como é necessário abrir a válvula na caldeira em que a pressão do vapor supera a resistência do seu corpo. E eis que a arte é, parece ser, o veículo adequado para atingir esse equilíbrio explosivo com o meio (VIGOTSKI, 1998, p. 312). 
Para o autor, desde as mais remotas épocas o significado da atividade estética foi entendido como uma catarse. Ou seja, um ato de criação que culmina em uma obra de arte é a resolução e uma liberação das paixões que torturam o sujeito. Não se trata simplesmente de lazer ou transmissão de sentimentos, é uma atividade de superação do psiquismo que não encontra vazão na vida cotidiana. Nesse sentido, o efeito da arte existe e se manifesta por meio de certo esclarecimento interno, de uma eliminação dos conflitos íntimos e, portanto, da liberação de algumas forças trancadas e deslocadas.

Em um caráter dialético, a contradição, a repulsa interna, a superação, a vitória, todos são componentes necessários ao ato estético. A arte é portadora desse comportamento dialético que reconstrói a emoção e, por isso, envolve a mais complexa atividade de uma luta interna dos indivíduos que é resolvida pela catarse. Para os autores, o principal aspecto da estética na experiência consiste no fato de as emoções serem submetidas à certa descarga, a sua destruição e transformação em contrários, ou seja, à complexa transformação de sentimentos que resultam em uma experiência modificadora do indivíduo.

Nesse sentido, a relação do seres humanos com o sensível - criada, expressada e sentida na forma de arte, objeto ou evento - é, portanto, essa descarga indispensável de energia em um procedimento complexo de equilíbrio do individuo com o meio. Consideram que é uma relação que estimula o processo criador, distintivo dos seres humanos, tanto para quem cria a arte (o artista) como para quem a recebe (o público). A refundição das emoções na experiência estética realiza-se por força de um sentimento social que foi objetivado, levado para fora do sujeito, materializado e fixado nos objetos externos, que se tornaram instrumento e patrimônio da humanidade.

Para Vecchi (2006), o sentimento estético pode nutrir um conhecimento que não se alimenta apenas da informação comunicada de forma lógica e racionalizada, mas que leve também a uma relação de sensibilidade e empatia com as coisas, solicitando a criação de distintas conexões.

Enfatiza, ainda, que o sentimento estético ocupa diversos campos e, portanto, não está ligado estritamente à arte. É uma aspiração de beleza encontrada em todos os povos, e em todas as culturas, atuais e do passado. Para a autora, basta olhar a história da espécie humana para encontrar, em diferentes épocas e culturas, a presença de um cuidado formal e atenção à dimensão estética. Tal cuidado não é dedicado somente às grandes obras de arte, mas a todos os testemunhos da vida humana nos quais emergem gestos de cuidado, busca de qualidade e beleza. 
Creio que a dimensão estética é uma atitude cotidiana, uma relação empática e sensível com o ambiente, um fio que conecta e une as coisas, um ar que leva a preferir um gesto a outro, a escolher um objeto, a escolher uma cor, um pensamento; escolhas em que harmonia, cuidado, prazer para a mente e os sentidos são percebidos. A dimensão estética pressupõe um olhar que descobre, que admira e se move. É o oposto da indiferença, da negligência e do conformismo (VECCHI, 2006, p. 15-16, tradução nossa).

Oswald (2011), refletindo sobre a dimensão estética do conhecimento na constituição do sujeito, desde a infância, também ressalta sua perspectiva cotidiana, sensível e social.

A experiência estética é aquela que sensibiliza, que emociona, não tem a ver necessariamente com o belo, com a contemplação de uma obra de arte, com um estado de transe que supostamente traz inspiração para o artista executar sua obra. Experimentar algo esteticamente é impregnar-se do mundo físico e social pelos sentidos (OSWALD, 2011, p. 25).

Sob essa perspectiva, deve-se ter em mente que o que é singular na formação do indivíduo é a ideia de que a pessoa se constitui num vínculo constante com o mundo. E o mundo, compreendido em sua pluralidade, que emerge também pela imaginação e fantasia, é algo que se associa às possibilidades contidas na experiência estética (HERMANN, 2010; DEWEY, 2010). Kramer (2005) corrobora com essa perspectiva ao afirmar que:

O que singulariza o ser humano é essa pluralidade de experiências, de valores e saberes presentes na dança, música, na produção de objetos, nas festas civis ou religiosas, nos modos de cuidar das crianças, da terra, dos alimentos, roupas, nas trajetórias contadas pelas famílias, grupos, etnias. Essa pluralidade cultural materializa-se também na literatura, no cinema, arte, música, fotografia, teatro, pintura, escultura, nos museus, na arquitetura (KRAMER, 2005, p. 08).

Para Kramer e Carvalho (2012), a experiência de crianças, jovens e adultos nos diversos espaços culturais pode contribuir no sentido de sensibilizar o olhar e propiciar situações de aprendizado do ponto de vista cultural, político, ético 
e estético. As autoras ressaltam o quanto os museus são espaços que detêm esse potencial para estimular os indivíduos na construção desse olhar sensível, que busca ver de outra maneira, contemplar outros ângulos e interpretar novos sentidos nas relações que ocorreram historicamente entre natureza, seres humanos e suas invenções.

Fallon e Chavepeyer (2013) consideram que, no encontro com obras e artefatos, os museus convidam a perceber, sentir e construir referências sobre o que se vê, unindo a experiência individual ao que é social. As referências povoam o imaginário, unem o indivíduo à história, a outros seres humanos, a outras culturas e à história da humanidade.

Durante a visita, podemos sentir interesse, espanto, diversão, estranheza, raiva ou podemos ficar entediados. E, de repente, quando entramos em uma sala, nos sentimos excitados e subitamente movidos por um detalhe ou pelo conjunto de uma obra. Nos sentimos unidos, reconhecidos, próximos àquele artista que expressa nossa própria intimidade tão bem. Esse trabalho será parte para sempre do nosso "museu interior", das nossas referências(...). Devemos permitir às crianças o treinamento inicial de seu "museu interior". Eles estão famintos por imagens, por representações, eles amam reconhecer o mundo que eles descobrem (FALLON; CHAVEPEYER, 2013, p. 8-9, tradução nossa).

Leite (2011) também destaca a qualidade estética diferenciada que os museus podem oferecer para o público infantil. Olhando mais de perto as obras e objetos que compõem o acervo - que expograficamente têm dimensões que não cabem nas páginas dos livros - as crianças (e os diversos públicos) podem perceber aspectos de forma diferenciada, mais sensível e atenta. Encontrando objetos do cotidiano ou de outras épocas (ou representações deles), sob uma nova organização estética e numa outra relação (delineada pelo discurso expositivo), pode-se deparar com o desconhecido bem como estranhar o que é familiar. 


\section{As crianças e a experiência museal em museus de Arte, Ciência e História}

$\mathrm{Na}$ época de realização da pesquisa, a Casa da Ciência da UFRJ (Universidade Federal do Rio de Janeiro) recebeu três exposições temporárias: a) "Aedes: que mosquito é esse?;" b) "Imagem e Miragem"; c) "Portinari-Arte e Meio Ambiente". Das três exposições, a primeira e a terceira foram visitadas por turmas de Educação Infantil. A exposição "Aedes: que mosquito é esse?" buscou contar, de forma lúdica e interativa com diversas tecnologias, algumas curiosidades da vida do mosquito vetor da dengue, zika, chicungunya e febre amarela. "Portinari - Arte e Meio Ambiente" foi uma exposição que, a partir de 23 réplicas das obras do artista Candido Portinari ${ }^{5}$, ressaltou a importância do extraordinário legado da fauna, da flora, da cultura e do povo brasileiro, propondo que o visitante repensasse a relação que se mantém entre as pessoas e a natureza.

O Museu Casa de Rui Barbosa apresentava sua exposição permanente que consiste na visitação da casa, em estilo neoclássico, antiga residência do diplomata Rui Barbosa ${ }^{6}$. Os ambientes do Museu permanecem próximos ao original, com as pinturas, os lustres, tapetes, objetos pessoais, vestuário e móveis que traduzem o ecletismo que dominou a arte e o modo de vida no final do século XIX e início do XX. O roteiro de visitas incluía também a garagem com viaturas antigas, a biblioteca infantojuvenil e o jardim musealizado por seu interesse histórico e artístico, que mantém a vegetação semelhante à da época de Rui Barbosa, que gostava de cultivar novas espécies.

O Museu de Arte do Rio estava exibindo concomitantemente três exposições: a) Dja Guata Porã: Rio de Janeiro indígena; b) Feito Poeira ao Vento: Fotografias da Coleção MAR; c) Dentro: Programa da Sala de Encontro. A exposição "Dja Guata Porã: Rio de Janeiro Indígena" apresentou a história do Estado do Rio de Janeiro como uma história indígena, e foi concebida com a colaboração de povos, aldeias e indígenas que residiam no estado ou na capital carioca. Obras, vídeos, fotografias e outros dispositivos, entrecruzados com documentação e iconografia, apresentavam uma linha do tempo que

5 Candido Portinari (1903-1962) foi um artista plástico brasileiro que participou de uma notável mudança na atitude estética e na cultura do país. Retratou em suas telas o povo brasileiro, superando aos poucos sua formação acadêmica e fundindo a ciência antiga da pintura a uma personalidade experimentalista a antiacadêmica moderna (SÃO PAULO, [1970]).

6 Intelectual brasileiro que se destacou como jurista, advogado, político, diplomata, escritor, filólogo, jornalista, tradutor e orador. Foi um dos organizadores da República, membro fundador da Academia Brasileira de Letras e defensor das liberdades civis (FUNDAÇÃO..., [1928]). 
contextualizava conceitos, períodos e acontecimentos. "Feito Poeira ao Vento" foi uma exposição fotográfica que buscava inserir a fotografia no campo da ficção e da reinvenção do mundo, destacando a interdisciplinaridade da fotografia e o quanto sua potência de criação dá suporte a plataformas diversas como o livro, o vídeo, a instalação, a pintura ou a performance. A exposição "Dentro" consistia em uma Sala de Encontro destinada a todos - e em especial a crianças e jovens - tendo como proposta promover um campo experimental de troca e aprendizado entre dois mundos: o da arte e o de quem a experimenta.

Observando essas exposições sendo visitadas por turmas de Educação Infantil, foi possível constatar que o encontro das crianças com os museus pode proporcionar experiências estéticas. Alicerçadas na elucidação teórica que nos ajuda a compreender a importância da dimensão estética nas experiências que compõem a formação dos sujeitos, desde a mais tenra idade, apresentamos a seguir a articulação que as crianças conseguem fazer entre o conteúdo das exposições e sua percepção / questionamentos / conhecimento de mundo.

\section{Expectativas, reações e os principais interesses das crianças nas exposições}

Com a atenção voltada para as reações que escapavam, ao modo como reagiam e às falas proferidas entre si, com os mediadores e com os professores, foi possível perceber que as crianças possuíam um entendimento sobre o que pode vir a ser um museu e o que esse local pode guardar. As expectativas, nas três instituições, giravam em torno do museu como local de infinitas possibilidades e aventuras a serem desbravadas. Quando questionadas sobre o que achavam que iriam encontrar dentro dos museus, dentre as diversas possibilidades de coisas fantásticas, o encontro com dinossauros era sempre uma hipótese presente nos grupos.

Mediador: Nesse lugar, vamos procurar uma coisa que eu quero saber se vocês conhecem. Crianças: Um avião / Uma baleia / Dinossauro / Um peixe / Um gigante / Eu já sei! É bem um tiranossauro Rex (Caderno de Campo - 2017 - Museu de Arte do Rio). 
As falas das crianças revelaram que o museu também é compreendido como lugar que guarda quadros e coisas antigas como mobiliários, louças, fotos etc. Algumas noções sobre normas de conduta socialmente esperadas também foram mencionadas pelas crianças. Entendimentos sobre o que não era permitido foram os mais presentes. No que concerne ao interesse pelo que era visto, foi possível perceber que, independente da tipologia do museu ou da temática abordada, o conteúdo expositivo atraia a atenção das crianças.

Na exposição indígena "Dja Guata Porã", do Museu de Arte do Rio, as crianças demonstraram grande interesse pelo acervo composto por esculturas, vídeos e objetos indígenas. Alguns eram conhecidos pelas crianças como arco, flecha, cestas e animais. Além da curiosidade sobre o acervo, as brincadeiras que se relacionavam com a fauna das matas brasileiras e com as músicas com instrumentos indígenas provocaram intensa participação das crianças. Tônicas e questionamentos como "Uaaaau, olha isso!", "O que é isso?", "Pode mexer?", "Deixa eu ver!" eram recorrentes. Uma reação também comum nos grupos que visitaram a Instituição foi o encantamento com o espaço e com a arquitetura do local. No terraço do Museu, relatavam para os colegas e para o mediador o que viam lá embaixo, o máximo que suas vistas conseguiam alcançar. Eram capazes de observar diferentes elementos da paisagem na Praça Mauá, como estátuas, relógios e até mesmo o mar e a poluição que havia na água.

No Museu Casa de Rui Barbosa, de modo geral, os três momentos da visita (contação de história, visita ao Museu-Casa e ao Jardim Histórico) despertavam o interesse das crianças. No Jardim - por ter mais espaço e poderem se locomover sem o controle das professoras - as crianças demonstraram estar mais à vontade. Também expressaram interesse pela natureza local com pequenos animais (peixes, formigas, pássaros), aventuraram-se ao atravessar uma ponte sobre o lago e tiveram a oportunidade de participar de brincadeiras como caça às esculturas.

$\mathrm{Na}$ Casa da Ciência da UFRJ, foi possível perceber que o foco principal de interesse das crianças residiu nos elementos da natureza que compunham as duas exposições que ocorreram ao longo do ano. Na exposição "Aedes: que mosquito é esse?", mesmo com todos os módulos interativos, as crianças se detiveram um tempo maior observando o conteúdo dos microscópios que continham as etapas morfológicas do inseto (ovos, larva, mosquito etc.). Já na exposição "Portinari e o Meio Ambiente", as crianças demonstraram grande interesse pelos elementos naturais que compunham a expografia como carvão, areia, terra, plantas etc.

Nas três instituições, as crianças demonstraram entrosamento e uma relação interativa e de troca com os mediadores e com suas propostas ao longo das visitas. Sentiam-se à vontade para fazer perguntas relacionadas ao que 
viam, imaginavam e/ou suspeitavam. No Museu de Arte do Rio, especialmente, ficavam envolvidas com as atividades e brincadeiras sugeridas e entravam no faz-de-conta estimulado pelos mediadores em diversos momentos.

Criança: Eu achei! Vem cá! Vou te mostrar [criança pega na mão do mediador de forma a conduzir ele e a turma em uma caçada sorrateira. Vão andando abaixadas, devagar, se escondendo e esquivando pelo acervo e sussurrando atrás da onça]. Mediador: Caramba! Ainda não achamos. Vamos cantar de novo a música da onça para ver se achamos ela? Mediador e Crianças: Eu vi uma onça gemer na mata do Arvoredo [todos rosnam]. Crianças: Acho que a onça está lá! / É! É a nossa onça. [observam o objeto empolgadas]. Criança: [põe a mão dentro boca da escultura em formato de onça] Aiii ela me mordeu! [algumas crianças ficam assustadas]. Mediador: Não morde não, porque essa onça é bem boazinha, né?! Criança: Pois é, ela não morde nada [conta gargalhando aos colegas que ficaram assustados] (Caderno de Campo - 2017 - Museu de Arte do Rio).

Conforme abordado por Vigotski (2009), para a formação e constituição da criança, a atividade criadora da imaginação age por meio da formulação de hipóteses a partir do que já sabe (de suas experiências anteriores) e do que pode vir a ser. Essa é uma condição que ocorre sempre que a criança não é subtraída a uma postura de reprodução.

O acervo da exposição "Dja Guata Porã", por diversas vezes, serviu como material para o faz-de-conta e contribuía para enriquecer o imaginário da fantasia das crianças, que descobriam a possibilidade de criar formas e significações a partir dos objetos vistos. Sobre essa perspectiva, Richter (2011) amplia a reflexão ao elucidar que real e imaginário são indissolúveis e o pensamento da criança se desenvolve com o jogo entre simulacro e realidade, onde tudo que vê e vive é passível de ser transmutado. Nesse sentido, a imaginação é a ferramenta que sustenta o sentir e o raciocínio, permitindo à criança criar e construir um imaginário social, constituído de cultura e na cultura e o faz-deconta é ferramenta fundamental nesse processo.

No contato com o acervo, as crianças faziam leituras criativas sobre o que viam, deixavam a curiosidade e a imaginação fruírem de forma a enxergar novos detalhes, construindo outras narrativas para as obras que, até então, não haviam sido consideradas pelos mediadores e professores. 
Mediador: Então os animais têm que estar livres, certo? Na floresta e não presos. Crianças: Isso! / Imagina só se o bico do passarinho fosse uma furadeira... ele ia poder fugir [da gaiola]! (Caderno de Campo 2017 - Casa da Ciência da UFRJ).

Por vezes, as crianças também apresentavam falta de interesse nas atividades propostas pelos mediadores. No Museu de Arte do Rio, em uma visita que o mediador utilizou como metodologia principal apenas a contação de história de vários contos indígenas, ao longo da visita, as crianças foram perdendo o entusiasmo.

Mediador: Agora vamos sentar aqui nesse tapete [Tapete de Histórias do povo Puri] que eu vou contar uma história para vocês. É um conto indígena. Criança: [crianças que estavam fazendo a visita com outro mediador entram correndo na exposição] $A$ gente quer correr também. Mediador: Daqui a pouco a gente corre [e continuou contando a história enquanto as crianças já dispersas observavam animadas a mediação do outro grupo] (Caderno de Campo - 2017 - Museu de Arte do Rio).

Igualmente, nos momentos em que os grupos eram submetidos a estratégias de amplo controle, as crianças demonstravam incômodo e cansaço, como na Casa da Ciência, em que os mediadores solicitavam, apenas para as crianças, que a cada obra observada todas se sentassem, no chão, em frente ao quadro. $\mathrm{Ou}$ como ocorreu em um dos grupos observados, onde a professora recomendava que, na locomoção pelo espaço, todas as crianças andassem de mãos dadas com sua "dupla".

Sobre práticas de controle, como andar em fila, dar as mãos ou manter a criança por longo tempo sentada para que observem os objetos dos museus, é importante destacar que a percepção do mundo para as crianças se dá pelos sentidos. Fallon e Chavepeyer (2013, p. 05) reiteram que além da "extraordinária acuidade sensorial, a criança pequena também é um ser motor: o movimento é vida". Portanto, querer manter as crianças quietas, por muito tempo, além de gerar conflitos no grupo, pode ser um fator de empobrecimento da experiência.

Em meio à descoberta dos diferentes espaços dos museus - que eram amplos e cheio de aventuras a serem desbravadas - algumas crianças demonstraram medo. Nesses momentos, o apoio e a empatia entre pares foram fundamentais para que as crianças que estavam receosas se arriscassem a entrar e explorar os ambientes. 
Crianças: Olha que legal, a gente vai atravessar uma ponte / Caramba! / Eu tenho medo. / Vamos lá, vem! [criança dá a mão para ajudar o colega com medo a atravessar a ponte no jardim] / Olha, aqui embaixo tem peixe / E passarinho (Caderno de Campo - 2017-Museu Casa de Rui Barbosa).

Criança: Cadê o urso? [pergunta assustado]. Mediador: $O$ urso já foi embora, ficou lá na caverna! Criança: Era só um negócio assim... para a gente fingir que teve. [criança fala para a colega tentando acalmá-la] (Caderno de Campo - 2017 - Museu de Arte do Rio).

Essa postura solidária adotada pelas crianças para desvendar os museus pôde ser observada no Museu de Arte do Rio e no Museu Casa de Rui Barbosa. No museu histórico, algumas crianças achavam a Casa escura e estranhavam alguns quadros antigos, já no museu de arte o medo do encontro com o desconhecido no espaço amplo era mais recorrente. Contudo, a solidariedade e a empatia entre as crianças foram percebidas de forma similar nas duas instituições - davam as mãos, proferiam palavras de apoio e esclareciam situações aos colegas.

Dewey (2002) salienta que por trás de todos os comportamentos visíveis da criança que experimenta esteticamente a cultura há o reajustamento de sua postura mental em uma perspectiva alargada e solidária, a consciência como poder crescente e a ampliação da capacidade de discernimento e das aptidões individuais com os interesses do mundo. Para o filósofo, trabalhar com a cultura de forma consistente é, seguramente, "o desenvolvimento da imaginação em termos de flexibilidade, âmbito e solidariedade" (DEWEY, 2002, p. 58). Nessas atitudes solidárias entre as crianças que se relacionavam com a cultura material dos museus, foi possível captar sinais dessa contribuição para a formação humana resultante da experiência estética vivida.

\section{Articulações entre o conteúdo das exposições e o conhecimento de mundo}

Outro aspecto da experiência vivida pelas crianças nos espaços museais, possível de ser captado, foi a articulação de saberes sobre a temática das exposições que as crianças conseguiam realizar tendo como alicerce o conhecimento de mundo que traziam consigo. Dewey (2010) considera que a experiência estética ocorre quando o espectador, assim como o criador da obra/objeto, passa por um processo de ordenação dos elementos de forma 
conjunta - entre o que é percebido e a bagagem de conhecimentos advindos das experiências anteriores do sujeito. $\mathrm{O}$ artista faz o trabalho de escolher, simplificar, esclarecer, abreviar e condensar tudo em determinada obra/objeto de acordo com seu interesse. Aquele que olha também precisa passar por essas etapas de acordo com seu ponto de vista e interesse. Desta forma, para ambos, ocorre uma reunião de detalhes e particularidades de conhecimentos anteriores dispersos que se reúnem em um todo vivenciado.

Nas visitas observadas, a partir do que viam nas exposições e no diálogo com os mediadores e com os professores, as crianças demonstraram inúmeras articulações de conhecimento sobre os diferentes conteúdos dos três museus investigados. Identificaram cores, objetos e formas geométricas; expuseram seus entendimentos sobre casas, mobiliários, temática indígena, diferentes animais, plantas, frutas, preservação do meio ambiente, o respeito à fauna e à flora, dentre outros assuntos. As interpretações que faziam partiam da relação que estabeleciam com suas experiências anteriores e conhecimentos prévios adquiridos no âmbito familiar e/ou escolar.

Criança: Que vaso é esse aqui? [fica impressionada com um vaso em meio a outros que estavam na sala]. Mediadora: $E$ um vaso que veio lá do Japão. Criança: Eu já vi coisas lá do Japão que soltam fogo (Caderno de Campo -2017 - Museu Casa de Rui Barbosa).

As crianças também demonstraram um entendimento das obras a partir de um olhar sensível para as diferentes linguagens artísticas que retratavam o sofrimento, a morte e a miséria.

Mediador: Ana Clara leu que o nome desse quadro é o vendedor de passarinhos. É legal isso? Crianças: Não! [todas respondem negativamente] / É uma maldade! / Por que existe vendedor de passarinhos? [exclama retoricamente indignada] / Lá em Campos quando o passarinho estava com a asa meio ruim e pousou lá na casa da minha avó, em Atafona, a gente colocou a água para ele e comida e ele não conseguiu, ai no dia seguinte ele já tinha morrido (Caderno de Campo - 2017 - Casa da Ciência da UFRJ). 
No Museu Casa de Rui Barbosa, evidenciaram curiosidade pelos objetos do acervo (vestuários, mobiliário, quadros etc.) e observaram aspectos da arquitetura, sinalizando diferenças das casas em que viviam. As perguntas eram constantes: a cada novo ambiente, indagavam quem eram as pessoas pintadas nos quadros, as utilidades dos móveis que desconheciam, relatavam suas impressões e buscavam resgatar conhecimentos de suas experiências anteriores.

No Museu de Arte do Rio, também foi possível perceber que as crianças faziam reflexões sobre o que viam nas exposições e sobre o que conheciam. Observavam as obras, faziam perguntas, expunham suas impressões, relacionavam seus saberes do cotidiano com o que viam nas fotografias e criavam suas hipóteses sobre o acervo indígena. Faziam observações e interpretações com seus pares e com o mediador - concordavam, discordavam, experimentavam outros pontos de vista.

\begin{abstract}
Mediador: [contando uma história indígena] $E$ sabe quem encontrou a cutia? Dois indios, mas eram dois indios crianças que a gente chama de Curumim. Criança: Eu conheço! Mediador: Conhece Curumim? Crianças: Sim! Porque lá na escola foram os índios. Mediador: Olha, que legal! Então, foram essas crianças indigenas, chamadas curumins, que encontraram a cutia que estava com muita fome. Criança: Eu tenho um livro que tem curumim. Mediador: Que bacana! (...). Criança: $O$ pai deles [curumins], que você falou, o nome é Pajé (Caderno de Campo - 2017 - Museu de Arte do Rio).
\end{abstract}

Dewey (2002) considera que quando a criança consegue expressar, de forma eloquente, a quantidade de informações assimilada de determinado assunto, diante de outros (professor, adultos, colegas), esse momento se caracteriza como um encontro social. Para o autor, quando o impulso verbal da criança é socialmente estimulado, há um contato contínuo com a realidade. $\mathrm{E}$, como resultado, a criança tem pensamentos que quer exprimir, o desejo social de relatar suas experiências e de ouvir as experiências de outros. Esse momento pode ser compreendido enquanto uma espécie de câmbio social onde as experiências e ideias são compartilhadas, sujeitas a críticas, possibilitando, assim, o delineamento de novas linhas de pensamento.

Leite (2005) coaduna com a perspectiva descrita acima e ressalta que, apesar do frequente enquadramento comportamental imposto ao público infantil nos museus, em sua capacidade de subversão da ordem, de transgressão, as crianças conseguem mergulhar em suas próprias experiências contemplativas 
exercendo o papel de sujeitos, capazes de fazer emergir no grupo ideias e compreensões singulares. Nesse sentido, fica visível que a criança contempladora é sujeito-interlocutor da obra, pois coloca em jogo seus referenciais e todo o seu conteúdo de significações para construir o entendimento da obra com a qual interage.

\section{Considerações finais}

Mediante às constatações supracitadas ao observar como as crianças reagem ao visitar museus com suas escolas, em diálogo com estudos teóricos do campo da dimensão estética na infância, podemos concluir que a experiência ocorrida nos espaços museais se constitui na interação com o(s) outro(s) (pares, professores, mediadores) e com as manifestações, registros e celebração das diferentes formas de viver e estar no mundo. Portanto, "os museus podem ser compreendidos enquanto meio - experimental e criativo - profícuo para promover experiências formativas às crianças a partir da interação com a cultura material" (LOPES, 2019).

Por guardar e expor de forma diferenciada os diferentes testemunhos da cultura material, os museus que se abrem para receber o público infantil podem provocar curiosidade, admiração, encantamento, estranhamento, discordância dentre tantos outros sentimentos - de modo a impulsionar a criança a desvendar o sentido dos objetos, com uma postura crítica e investigativa perante às coisas do mundo. No encontro com esses objetos expostos nos museus, em meio à linguagem expositiva e à leitura de mundo compartilhada entre os diferentes agentes da visita (crianças - professores - educadores do museu), a criança pode relacionar emoções, pensamentos e experiências. Desta forma, suas descobertas, percepções e compreensões são enriquecidas.

Contudo, a literatura sobre o tema aponta que o desconhecimento acerca das especificidades da infância reflete-se tanto na pouca oferta de atividades nos museus, quanto no despreparo da recepção e na limitação dos educadores (mediadores e professores) para aproveitar as distintas possibilidades a serem exploradas nesses espaços com as crianças. Essa falta de preparo na formação dos educadores (da escola e do museu) evidencia a lacuna entre as instituições universitárias, museológicas e escolares na troca de saberes e experiências. Portanto, é necessário que se amplie a troca de saberes entre museus, escola e universidade com o intuito de diminuir a lacuna entre os estudos sobre a infância e as práticas educativas com as crianças nos espaços culturais. 


\section{REFERÊNCIAS}

CARVALHO, Cristina. Criança menorzinha...ninguém merece! - políticas de infância em espaços culturais. In: KRAMER, Sonia; ROCHA, Eloísa Candal (org.). Educação infantil: enfoques em diálogo. São Paulo: Papirus, 2013. p. 295-312.

CARVALHO, Cristina. Quando a escola vai ao museu. Campinas, SP: Papirus, 2016.

CARVALHO, Cristina; LOPES, Thamiris. O público infantil nos museus. Revista Educação e Realidade, Porto Alegre, v. 41, n. 3, p. 911-930, jul./set. 2016.

DEWEY, John. A escola e a sociedade e a criança e o currículo. Lisboa: Relógio D’Água Editores, 2002.

DEWEY, John. Arte como experiência. São Paulo: Martins Fontes, 2010.

FALLON, Charlotte; CHAVEPEYER, Isabelle. Manifesto: museos de arte amigos de los niños pequenos. Bruxelas: Teatro de la Guimbarde y del FRAJE, 2013.

FUNDAÇÃO Casa de Rui Barbosa. Principal. Rio de Janeiro, [1928]. Disponível em: http://www.casaruibarbosa.gov.br/index.php. Acesso em: 16 abr. 2018.

GABRE, Solange. Para habitar o museu com o público infantil: uma proposta de formação colaborativa entre professores da infância e profissionais do Museu Municipal de Arte de Curitiba. 2016. Tese (Doutorado em Educação) - Universidade Federal do Rio Grande do Sul, Porto Alegre, 2016.

LEITE, Maria Isabel. Museus de Arte: Espaços de educação e cultura. In: LEITE, Maria Isabel; OSTETTO, Luciana Esmeralda (org.). Museu, educação e cultura: Encontros de crianças e professores com a arte. Campinas, SP: Papirus, 2005.

LEITE, Maria Isabel. Museu, criança e brincadeira: combinação possível? In: ALMEIDA, Marcos Teodorico. O brincar e a brinquedoteca: possibilidades e experiências. Fortaleza: Premius, 2011. p. 41-55.

LOPES, Thamiris. Outras formas de conhecer o mundo: Educação Infantil em museus de arte, ciência e história. 2019. Tese (Doutorado em Educação) - Pontifícia Universidade Católica do Rio de Janeiro, Rio de Janeiro, 2019.

MARTINS, Mirian; PICOSQUE, Gisa; GUERRA, Maria Terezinha. Didática do Ensino de arte: a língua do mundo: poetizar, fruir e conhecer a arte. São Paulo: FTD,1998.

MOURA, Maria Teresa. Arte e infância: interações de crianças, adultos e obras de artes em museus. In: ROCHA, Eloisa Candal; KRAMER, Sônia (org.). Educação infantil: Enfoques em diálogo. Campinas, SP: Papirus, 2011. p. 103-120.

OSWALD, Maria Luiza. Educação pela carne: estesia e processos de criação. In: PASSOS, Mailsa Carlos Pinto; PEREIRA, Rita Ribes (org.). Educação experiência estética. Rio de Janeiro: Nau, 2011. p. 23-38. 
OLIVEIRA, Alessandra. Museu: Um lugar para a imaginação e a educação das crianças pequenas. In: KRAMER, Sonia; ROCHA, Eloisa Candal (org.). Educação Infantil: Enfoques em diálogo. Campinas: Papirus, 2011. p. 313-330.

PILLAR, Analice Dutra (org.). A educação do olhar no ensino das artes. Porto alegre: Mediação, 2011.

POL, Elena; ASENSIO, Mikel. La Historia Interminable: una visión crítica sobre la Gestión de Audiencias Infantiles em Museos. MUSA Revista de los Museos de Andalucía, Andalucía, Espanha, v. 4, p. 11-20, 2006.

REDDIG, Amalhene. A infância representada nos espaços museais de Santa Catarina: reflexões sobre educação, identidade cultural, museus, arte e infância. 2007. Dissertação (Mestrado em Educação) - Universidade do Extremo Sul Catarinense, Criciúma (SC), 2007.

RICHTER, Sandra. Infância e imaginação: o papel da arte na Educação Infantil. In: PILLAR, Analice Dutra (org.). A educação do olhar no ensino das artes. Porto alegre: Mediação, 2011. p. 181-198.

SÃO PAULO (Estado). Secretaria de Cultura e Economia Criativa. Museu Casa de Portinari. Brodowski, SP, [1970]. Disponível em: https:/www.museucasadeportinari. org.br. Acesso em: 15 mar. 2021.

SHAFFER, Sharon. Engaging Young Children in Museums. New York: Routledge, 2015.

VECCHI, Vea. Estética y aprendizaje. In: HOYUELOS, Alfredo. La estética em el pensamiento y obra pedagógica de Loris Malaguzzi. Barcelona: Octaedro; Rosa Sensat, 2006. p. 15-26.

VIGOTSKI, Liev. Psicologia da Arte. São Paulo: Martins Fontes, 1998.

VIGOTSKI, Liev. Psicologia Pedagógica. Porto Alegre: Artmed, 2003.

VIGOTSKI, Liev. Imaginação e criação na infância: ensaio pedagógico: livro para professores. São Paulo: Ática, 2009.

Texto recebido em $31 / 08 / 2020$.

Texto aprovado em 25/11/2020. 